\title{
Communicating with patients requiring anti-VEGF intravitreal injections and their families during the COVID-19 pandemic: an update
}

\author{
Jean-François Korobelnik ${ }^{1,2}$ (D) Anat Loewenstein ${ }^{3}$ - on behalf of the Vision Academy
}

Received: 26 November 2020 / Revised: 26 November 2020 / Accepted: 4 December 2020 / Published online: 7 January 2021

(C) The Author(s) 2021

Dear Editor,

In Spring 2020, with our colleagues at The Vision Academy [1], we identified the need for clinician guidance on how best to communicate with patients and caregivers to ensure crucial eye care appointments and services were continued during the current COVID-19 pandemic. At that time, we noted, in particular, heightened anxiety levels among patients, receiving intravitreal injections of anti-vascular endothelial growth factor (VEGF) for neovascular age-related macular degeneration (nAMD), who need to attend regular ophthalmology appointments to maintain their vision. We therefore published guidance for managing such patients during the acute phase of the COVID-19 pandemic [2] and supported this with a patient communication template. The communication could be sent via e-mail, post, or text messages ahead of appointments to reassure patients and caregivers that their safety and eye health remained a priority [3].

Since then, the COVID-19 pandemic has escalated: clearly, it is not going to disappear quickly, and we need to make the necessary adjustments to establish a routine of safely treating patients while the pandemic is ongoing. Evidence has emerged that people with moderate/severe visual impact are significantly more likely to experience worsened mental health because of COVID-19-related restrictions than those with mild/no visual impairment [4]. Additionally, a UK study found that approximately $50 \%$ of patients with nAMD failed

This article is part of a Topical Collection on Perspectives on COVID-19

Jean-François Korobelnik

jean-francois.korobelnik@chu-bordeaux.fr

Service d'Ophtalmologie, CHU Bordeaux, Bordeaux, France

2 Inserm, Bordeaux Population Health Research Center, team LEHA, Université de Bordeaux, UMR 1219, F-33000 Bordeaux, France

3 Division of Ophthalmology, Tel Aviv Medical Center, Sackler Faculty of Medicine, Tel Aviv University, Tel Aviv, Israel to attend a scheduled hospital or clinic appointment [5]. Of those non-attendees, $85 \%$ said they were fearful of contracting COVID-19, and over $70 \%$ would have attended if they had been given clear advance information of adequate infection control measures. These findings are understandable given patients with nAMD are at increased risk of COVID-19related complications, hospitalization, and mortality because of increased age with comorbid conditions. They also reinforce the need for patient information tools.

We now provide greater detail about the implementation of patient guidance according to the local epidemic situation, based on three (risk) tiers, until such time that long-term solutions (e.g., effective vaccine) are available [6]:

1. The effective reproduction number, $R_{t}$, is $<1$, but herd immunity through mass vaccination has not yet been achieved

2. $R_{t}$ is $\approx 1$, and local COVID-19-positive clusters result in a relatively high risk of contracting COVID-19, although local hospital resources are not critically overwhelmed

3. $R_{t}$ is $>1$, and hospital resources are under current or imminent risk of significant pressure, with higher number of local or national restrictions likely

For each scenario, we provide guidance on prioritizing patients according to clinical need, while minimizing risk for patients and healthcare professionals.

The Vision Academy has also endorsed a new 'Dear Patient' letter and two accompanying infographics with the goals of clear communication to minimize patient/caregiver anxiety and maximize clinic attendance. Three color-coded tiers (green, yellow or red) indicate simply the level of risk and, most importantly, the precautions that are in place to ensure the safety of patients and their caregivers (Fig. 1). It is very important that appointments are not missed especially during treatment phases. 


\begin{tabular}{|c|c|}
\hline \multirow{5}{*}{$\begin{array}{l}\text { Rates of infection remain at a low level } \\
\text { Public health measures are less restricted but } \\
\text { social distancing measures remain critical }\end{array}$} & Clinic staff are regularly tested as appropriate \\
\hline & Patients and accompanying individuals are asked to wear a mask \\
\hline & Appointments may be rescheduled if patients are unwell \\
\hline & Number of people allowed in the waiting room may be limited \\
\hline & Appointments will be brief and some regular tests might sometimes be skipped \\
\hline \multirow{4}{*}{$\begin{array}{l}\text { Increase in infection rates } \\
\text { New public health measures implemented }\end{array}$} & As green plus: \\
\hline & Regular eye examinations might be skipped, although treatment would be given \\
\hline & Some injection schedules may be changed to avoid additional monitoring \\
\hline & Some non-essential / non-urgent appointments may be postponed \\
\hline \multirow{5}{*}{$\begin{array}{l}\text { High rates of infection } \\
\text { Strict public health measures have been } \\
\text { implemented }\end{array}$} & As green and yellow plus: \\
\hline & A pre-appointment telephone or video call may be required to see if the clinic \\
\hline & visit is essential or if the appointment can be postponed \\
\hline & Patients requiring regular treatment to preserve sight will be prioritized \\
\hline & Non-urgent appointments will be re-scheduled \\
\hline
\end{tabular}

All patients should regularly monitor vision at home and contact the clinic immediately if vision changes

Fig. 1 Description of main clinic procedural adaptations during the COVID-19 pandemic according to local epidemic situation, summarized from the patient infographic

Educational material in the form of infographic patient factsheets highlights characteristics for each of the three risk scenarios (and include an Amsler Grid) and provide patients with information on maintaining and improving their mental wellbeing alongside their eye health. When patients are unable to attend the clinic, they must re-schedule the appointment as quickly as possible and monitor their vision in the meantime. Should any change in their vision occur, patients are asked to re-contact the clinic.

We encourage the ophthalmic community to download these patient materials from https://www.visionacademy.org/ vision-academy-community/COVID-19-materials and adapt them for local use. Regionally, campaigns to call patients and encourage them not to miss examinations and treatments should be considered.

Prof. Jean-François Korobelnik

Prof. Anat Loewenstein

Funding Editorial support was provided by Apothecom, UK, and it was funded by Bayer Consumer Care AG, Switzerland

\section{Compliance with ethical standards}

Conflict of interest Jean-François Korobelnik is a consultant for Allergan, Bayer, Kanghong, Novartis, and Roche. Anat Loewenstein is a consultant for Allergan, Bayer, Kanghong, Novartis, Roche, ForSight Labs, and Notal Vision.

Open Access This article is licensed under a Creative Commons Attribution 4.0 International License, which permits use, sharing, adaptation, distribution and reproduction in any medium or format, as long as you give appropriate credit to the original author(s) and the source, provide a link to the Creative Commons licence, and indicate if changes were made. The images or other third party material in this article are included in the article's Creative Commons licence, unless indicated otherwise in a credit line to the material. If material is not included in the article's Creative Commons licence and your intended use is not permitted by statutory regulation or exceeds the permitted use, you will need to obtain permission directly from the copyright holder. To view a copy of this licence, visit http://creativecommons.org/licenses/by/4.0/.

\section{References}

1. Vision Academy People, Research Education. Available from https://www.visionacademy.org/vision-academy-community/aboutthe-vision-academy [Accessed on 29 October 2020]

2. Korobelnik J-F, Loewenstein A, Eldem B, Joussen AM, Koh A, Lambrou GN, Lanzetta P, Li X, Lövestam-Adrian M, Navarro R (2020) Guidance for anti-VEGF intravitreal injections during the COVID-19 pandemic. Graefes Arch Clin Exp Ophthalmol 258: 1149-1156

3. Korobelnik J-F, Loewenstein A, Vision Academy Steering Committee (2020) Communicating with patients with nAMD and their families during the COVID-19 pandemic. Graefes Arch Clin Exp Ophthalmol 258:1335-1337

4. Ting DSJ, Krause S, Said DG, Dua HS (2020) Psychosocial impact of COVID-19 pandemic lockdown on people living with eye diseases in the UK. Eye. https://doi.org/10.1038/s41433-020-01130-4

5. Fung TH, Kuet ML, Patel MK, Puri P (2020) Addressing COVID-19 fear to improve clinic attendance for patients with wet age-related macular degeneration. Acta Ophthalmol. https://doi.org/10.1111/ aos. 14520

6. Korobelnik J-F, Loewenstein A, Eldem B, Joussen AM, Koh A, Lambrou GN, Lanzetta P, Li X, Lövestam-Adrian M, Navarro R, Okada AA, Pearce I, Rodríguez FJ, Wong DT, Wu L (2020) AntiVEGF intravitreal injections in the era of COVID-19: responding to epidemic pressure. Graefes Arch Clin Exp Ophthalmol (in press)

Contributing authors Prof. Tariq Aslam, Consultant Ophthalmologist, Manchester Royal Eye Hospital, UK

Dr. Jane Barratt, Secretary General, International Federation on Ageing, Canada 
Prof. Bora Eldem, Professor of Ophthalmology, Hacettepe University, Turkey

Prof. Robert Finger, Professor of Ophthalmic Epidemiology and Retina Consultant, University of Bonn, Germany

Prof. Richard Gale, Consultant Medical Ophthalmologist and Clinical Director in Ophthalmology, Honorary Visiting Professor, University of York, UK

Dr. Monica Lövestam-Adrian, Head of the Medical Retina Department, Lund University Hospital, Associate Professor in Ophthalmology, Lund University, Sweden

Dr. Mali Okada, Royal Victorian Eye and Ear Hospital, Australia

Mr. Nick Parker, International Agency for Prevention of Blindness, UK

Dr. Francisco Rodriguez, Scientific Director, Fundación Oftalmológica Nacional, Chair of the Department of Ophthalmology, Universidad del Rosario School of Medicine, Colombia
Ms. Michelle Sylvanowicz, Director of Global Advocacy, Bayer, Switzerland

Mr. James Talks, Consultant Ophthalmologist, Royal Victoria Infirmary, UK

Prof. Tien Yin Wong, Professor and Medical Director, Singapore National Eye Centre, Duke-NUS Medical School, National University of Singapore, Singapore

Publisher's note Springer Nature remains neutral with regard to jurisdictional claims in published maps and institutional affiliations. 